\title{
Mice with a severe deficiency in protein C display prothrombotic and proinflammatory phenotypes and compromised maternal reproductive capabilities
}

\author{
Angelina J. Lay, 1,2,3 Zhong Liang, ${ }^{1,3}$ Elliot D. Rosen,1,3 and Francis J. Castellino, 2,3 \\ ${ }^{1}$ W.M. Keck Center for Transgene Research, ${ }^{2}$ Walther Cancer Center, and ${ }^{3}$ Department of Chemistry and Biochemistry, \\ University of Notre Dame, Notre Dame, Indiana, USA.
}

\begin{abstract}
Anticoagulant protein C (PC) is important not only for maintenance of normal hemostasis, but also for regulating the host immune response during inflammation. Because mice with a designed total genetic deficiency in PC $\left(\mathrm{PC}^{-/-}\right.$mice $)$die soon after birth, attempts to dissect $\mathrm{PC}$ function in various coagulation/inflammationbased pathologies through use of mice with less than $50 \%$ of normal PC levels have not been successful to date. In the current investigation, we have used a novel transgenic strategy to generate different mouse models expressing 1-18\% of normal PC levels. In contrast to $\mathrm{PC}^{-/-}$mice, mice with only partial PC deficiency survived beyond birth and also developed thrombosis and inflammation. The onset and severity of these phenotypes vary significantly and are strongly dependent on plasma PC levels. Our findings additionally provide the first evidence that maternal PC is vital for sustaining pregnancy beyond 7.5 days postcoitum, likely by regulating the balance of coagulation and inflammation during trophoblast invasion. These low PC-expressing transgenic mouse lines provide novel animal models that can be used to elucidate the importance of PC in maintenance of the organism and in disease.
\end{abstract}

\section{Introduction}

Protein $\mathrm{C}(\mathrm{PC})$ is a key component of the natural anticoagulant pathway that provides a negative feedback mechanism for the control of blood coagulation (1). Activation of PC to the serine protease activated PC (aPC) occurs on the surface of activated ECs when thrombin binds to its high-molecular-weight surface receptor, thrombomodulin (TM) (2). The catalytic efficiency of the thrombin-TM complex is enhanced in the presence of the EC $\mathrm{PC}$ receptor (EPCR), $\mathrm{Ca}^{2+}$, and the nonproteolytic cofactor protein $\mathrm{S}$ (3). Once activated, aPC inhibits thrombin formation by rapidly catalyzing inactivation of factor Va (FVa) (4) and FVIIIa (5) through limited proteolysis. PC also controls fibrin degradation by attenuating the activity of plasminogen activator inhibitor-1 (6), thereby increasing the plasma concentration of plasmin, which consequently further maintains blood fluidity.

The importance of the PC pathway in regulating hemostasis is clear in clinical settings wherein patients identified as having congenital or acquired deficiencies in this pathway present with thrombotic complications, e.g., superficial and deep vein thrombosis (7), pulmonary embolism (8), purpura fulminans (9), and, occasionally, arterial thrombosis with resulting stroke (10) and/or pulmonary arterial hypertension (11). More recently, a direct or indirect role for aPC in inflammation has been increasingly recognized, and it is known that this enzyme plays an important role

Nonstandard abbreviations used: aPC, activated PC; aPTT, activated partial thromboplastin time; BALF, bronchoalveolar lavage fluid; EPCR, EC PC receptor; FVa, factor Va; mPC, mouse PC; PC, protein C; P-Sel, P-selectin; TAT, thrombin-antithrombin; TM, thrombomodulin.

Conflict of interest: The authors have declared that no conflict of interest exists.

Citation for this article: J. Clin. Invest. 115:1552-1561 (2005).

doi:10.1172/JCI24030. in protecting the host against bacterial infection (12-14). In fact, systemic administration of aPC has been used clinically for the treatment of a subpopulation of patients with severe sepsis (15).

The involvement of PC in these numerous syndromes underlines the need for an animal model of severe PC deficiency for study and identification of potential drug targets in diseases related to the PC deficiency state. However, mice with a targeted total deletion of the PC gene $\left(\mathrm{PC}^{-/-}\right)$do not survive the neonatal period (16), which thus prevents investigation of $\mathrm{PC}$ function in mature $\mathrm{PC}^{-/}$mice. While heterozygous deficient $\mathrm{PC}$ mice $\left(\mathrm{PC}^{+/-}\right)$do survive the early lethality, live to adulthood, and can be successfully employed in some disease models $(17,18)$, the approximately $50 \%$ level of PC in these mice is often too high to observe spontaneous phenotypes and is not reflective of symptomatic patients. Thus, we sought a manner of generating mice with a severe genetic PC deficiency via transgenic approaches. In this investigation, we have succeeded in developing mice expressing very low levels of PC using a novel, cosmid-based transgenic strategy and have characterized these mice with regard to the role of the Proc gene in embryonic development and in development of spontaneous thrombosis- and inflammation-based phenotypes.

\section{Results}

Generation of transgenic mice expressing very low levels of PC. The strategy designed to generate $\mathrm{PC}$-insufficient mice employed a mouse $\mathrm{PC}(\mathrm{mPC})$ transgene that would allow a low level of PC expression in a $P C^{-/-}$background. For this, we used a cosmid-based approach, with an FVII-FX chromosomal fragment that was minimally altered to contain an inactivated FVII gene, followed sequentially by the complete $5^{\prime}$ proximal FVII-FX intergenic region (19), and an inactivated FX gene. This chromosomal segment provided the entire 
A
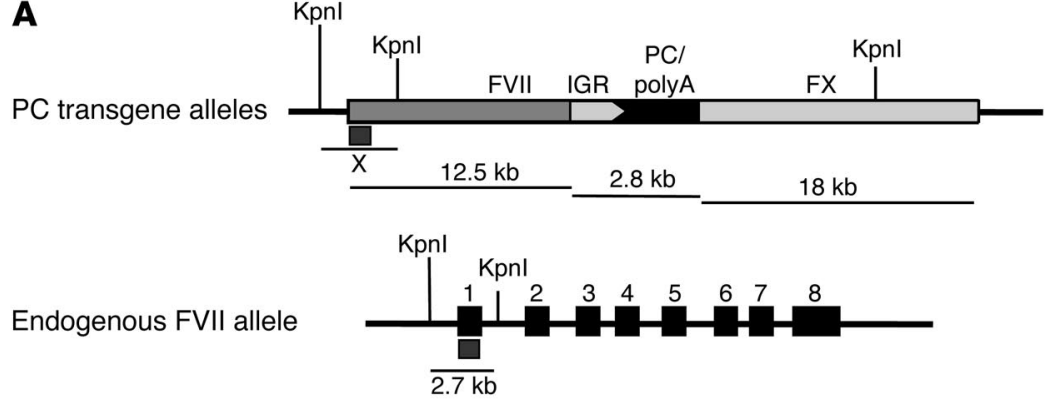

B

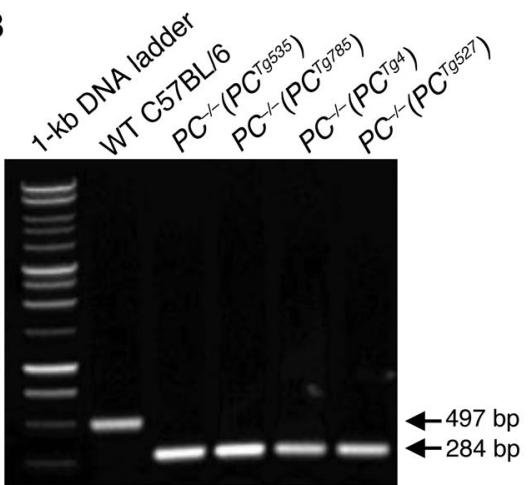

C

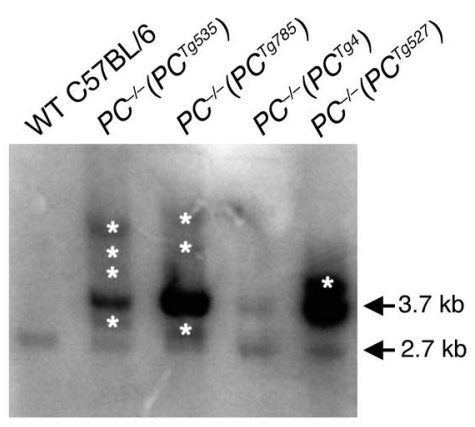

Figure 1

Generation of low-PC transgenic mice. (A) Schematic diagram showing relevant features of the low PC DNA construct. A $12.5-\mathrm{kb}$ fragment of an inactivated (by partial promoter deletion $\mathrm{FVII}$ gene and an 18-kb fragment of an inactive (by exon 1 deletion) FX gene were cloned upstream and downstream, respectively, of the PC cDNA/polyA sequences. Expression of $\mathrm{PC}$ was driven by the FX promoter contained within the complete intergenic region (IGR) of the FVII-FX chromosomal segment. (B) Low-PC potential founders were identified by PCR analysis. The sense and antisense primers spanned exons 4 and 6 of the $P C$ gene, respectively, amplifying a 497-bp fragment for the WT allele and a 284-bp fragment for the MPC cDNA that is derived from the transgene. (C) Low-PC transgenic mice from various lines were evaluated by Southern blot analysis of Kpnl-digested genomic DNA. The Southern probe in A hybridized to a 2.7-kb fragment of the WT FVII gene in addition to various PC transgene fragments (asterisks), the sizes of which are dependent on sites of PC transgene integration. The 3.7-kb band shows that at least 1 tandem repeat of the transgene has occurred in each mouse line.

upstream promoter region of the $F X$ gene (20). In turn, this should allow appropriate temporal and spatial expression patterns, as well as proper $\gamma$-carboxylation, of the downstream PC cDNA, which has characteristics similar to those of FX. Since much less is currently known about the characteristics of the promoter elements of the murine $P C$ gene, the use of the known proximal promoter of the $F X$ gene was the preferred approach. In addition, the utilization of this large chromosomal fragment was anticipated to minimize the potential influence of neighboring genes on $P C$ transgene expression. Finally, the PC cDNA sequence was inserted downstream of this $F X 5^{\prime}$ promoter, since use of the PC CDNA, rather than the $P C$ gene, would be expected to result in significantly reduced levels of PC expression, and this was the desired goal of the design. The final construct is diagrammed in Figure 1A.

The cosmid containing the PC cDNA was microinjected into C57BL/6 zygotes to generate PC transgenic founders. We screened a total of 84 potential founders for the presence of the PC transgene using a PCR strategy that differentiated between the endogenous $P C$ gene and the mPC cDNA derived from the inserted transgene. Positive founders were identified by the presence of a 284-bp PCR fragment representing the PC cDNA (Figure 1B). The 497-bp PCR amplicon corresponds to a fragment of the endogenous $P C$ gene (Figure 1B). However, this PCR approach does not distinguish $\mathrm{PC}^{+/-}$ from $P^{+/ /}$mice. Thus, a second PCR analysis was employed for differentiating between the WT and null alleles in 2 groups of mice. Once identified, the $P C^{+/-}$mice were mated with $P C$ transgenic founders $\left[P C^{+/+}\left(P C^{T g}\right)\right]$ to generate $P C^{+/-}\left(P C^{T g}\right)$ offspring. Further breeding of these offspring with $\mathrm{PC}^{+/-}$mice generated progeny with total inactivation of both WT PC alleles but containing the PC transgene $\left[\mathrm{PC}^{-1-}\left(P \mathrm{C}^{\mathrm{Tg}}\right)\right]$.

The pattern of $\mathrm{PC}$ transgene integration was analyzed by Southern blot hybridization of genomic DNA digested with KpnI. Hybridization using a $5^{\prime}$ probe for exon 1 of the FVII gene (Figure 1, A and C) resulted in a $2.7-\mathrm{kb}$ band representing 2 copies of the endogenous FVII gene, which thus served as an internal control. Each transgenic mouse line contained at least 2 integration sites, indicated by the presence of different-sized PC transgene fragments. In addition, each represents a unique line distinguishable by variations in integration patterns. The 3.7-kb fragment (Figure 1C) was consistent with the PC transgene integrated in tandem repeats, and this signal was found in all transgenic lines. The fragment intensity indicated multiple copies of the $P C$ transgene and demonstrated that several different founder lines with potentially different levels of PC expression were obtained. $\mathrm{PC}^{-/-}$ progenies followed the predicted Mendelian inheritance distribution. Consistent with a previous report (16), $P C^{-/-}$embryos lacking the $P C$ transgene died soon after birth. In contrast, $P C^{-/}\left(P C^{T g}\right)$ mice survived the neonatal lethality. This approach led to the generation of 4 novel, low PC-expressing transgenic mouse lines.

Spontaneous thrombosis in low-PC transgenic mice. Plasma PC was determined in all of the transgenic lines using plasmid (pIRESNeo-mPC) antibodies specific for mPC, developed in our laboratory, in an ELISA format. The PC antigen level was not measurable in $\mathrm{PC}^{-1-}\left(\mathrm{PC}^{\mathrm{Tg} 535}\right)$ mice, which suggests a very low $(<1 \%)$ level of WT PC in this transgenic line. This finding was consistent with the early onset and severity of thrombotic phenotypes associated with these mice. The detectable levels of plasma PC in other transgenic lines represent $1 \%, 3 \%$, and $18 \%$ of WT levels for $P C^{-/-}\left(P C^{T g^{T}}\right), P C^{-/-}\left(P C^{T g^{785}}\right)$, and $P C^{-/}\left(P C^{T^{T} 527}\right)$ mice, respectively (Figure 2A). In these mice, plasma PC levels strongly correlated with survival profiles (Figure $2 \mathrm{~B}$ ), with the poorest neonatal survival shown by $P C^{-1-}\left(P C^{T g 535}\right)$ mice when compared with $P C^{-1-}\left(P C^{T_{8} 4}\right)$, $P C^{-1-}\left(P C^{T g^{785}}\right)$, or $P C^{-1-}\left(P C^{T g 527}\right)$ littermates. The strain-specific plasma $\mathrm{PC}$ levels also reflect the considerable differences in spontaneous phenotypes. Mice from the $P C^{-1-}\left(P^{T}{ }^{T g 527}\right)$ transgenic line expressed $18 \%$ of WT PC levels, compared to less than $4 \%$ found in $\mathrm{PC}^{-/-}\left(\mathrm{PC}^{\mathrm{T}_{3} 4}\right)$ or $\mathrm{PC}^{-/-}\left(\mathrm{PC}^{\mathrm{T}_{\mathrm{g}} 785}\right)$ mice. This correlates with the lack of gross prothrombotic phenotypes in the transgenic mouse line expressing the highest levels of PC. 

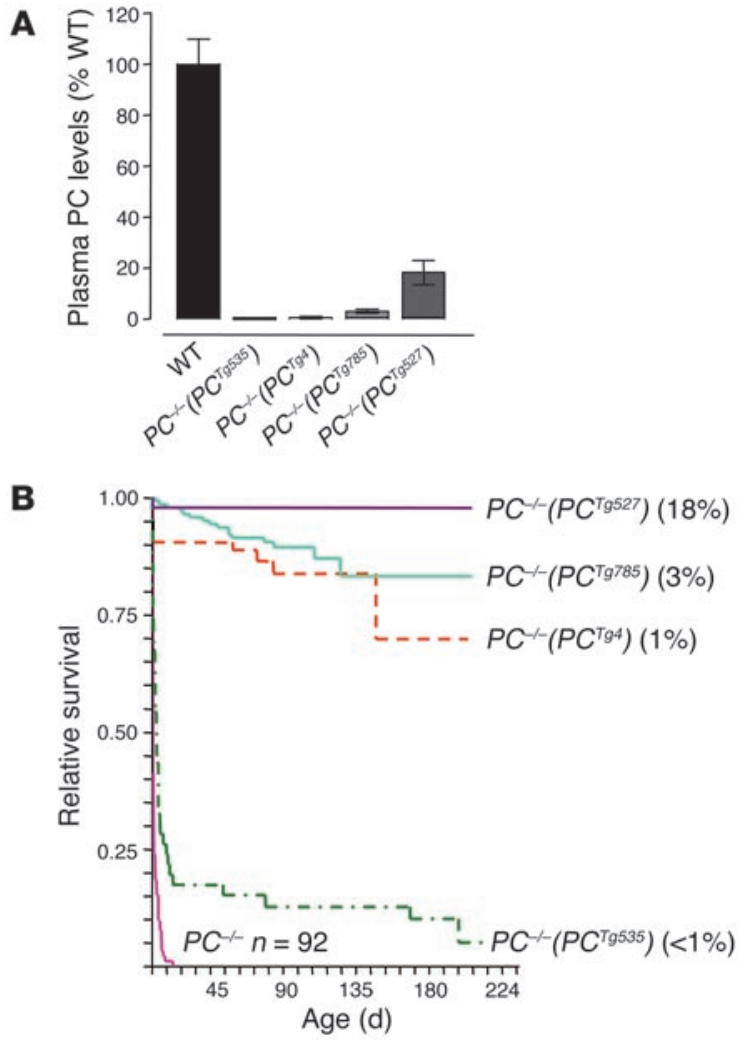

The majority of $\mathrm{PC}^{-/-}\left(\mathrm{PC}^{\mathrm{Tg} 535}\right)$ survivors developed early-onset hemorrhage that typically affected their legs and tails, leading to spontaneous amputation of the individual extremities or the entire legs and tails (Figure 3, A and B). Only $2 \%$ of these neonates survived to 6 months of age. Similarly, survivors from the $\mathrm{PC}^{-1-}\left(\mathrm{PC}^{\mathrm{Tg}} 4\right)$ and $\mathrm{PC}^{-1-}\left(\mathrm{PC}^{\mathrm{Tg} 785}\right)$ transgenic lines were also susceptible to thrombosis and hemorrhage, most frequently in the tails and feet (Figure 3, C-E). However, the disease onset of these latter mice was markedly different from that of $P C^{-/-}\left(P C^{T g 535}\right)$ mice, as offspring of $P C^{-1-}\left(P C^{T g} 4\right)$ or $P C^{-/-}\left(P C^{T g 785}\right)$ mice developed thrombotic phenotypes only after 3 months of age. Necrosis of the paws/legs was often accompanied by severe edematous swelling. Other macroscopically observable phenotypes included necrosis of the ear and the face (Figure 3, F and G). Despite their overall longer survival tendencies, $10 \%$ of progenies of $\mathrm{PC}^{-/-}\left(\mathrm{PC}^{\mathrm{Tg} 4}\right)$ and $P C^{-/-}\left(P C^{T g 785}\right)$ transgenic lines died spontaneously or were euthanized due to advanced disease. Macroscopic evidence of soft tissue hemorrhage was typically noted at postmortem examination. Evidence of focal hemorrhage was present in lungs, leg muscles, tails, paws, and in severe cases, associated localized necrosis in the lobes of the liver (Figure 3, H-J).

We determined tail bleeding times for $\mathrm{PC}^{-/-}\left(\mathrm{PC}^{\mathrm{Tg} 785}\right)$ mice at 4, 8 , and 12 weeks of age to further discern whether their thrombotic phenotypes precede a hemorrhagic condition. Significant differences in bleeding times in $P C^{-/-}\left(P C^{\operatorname{Tg} 785}\right)$ mice at various ages were observed. At 4 weeks, there were no statistical differences in bleeding times between $P C^{-1-}\left(P C^{T g 785}\right)$ and WT mice. Similarly, bleeding times for WT mice at 8 and 12 weeks of age were comparable to those of the 4-week-old mice. In contrast, low-PC mice at 8 weeks of age showed a prothrombotic phenotype, as evidenced by a significantly shorter bleeding time. At 12 weeks, these mice

\section{Figure 2}

$\mathrm{PC}$ levels correlate with poor survival in unchallenged low-PC mice. (A) Plasma PC levels were measured in mice derived from WT and the various low-PC transgenic lines using ELISA methodology. In $P C^{-/-}\left(P C^{T g 535}\right), P C^{--}\left(P C^{T g 4}\right), P C^{--}\left(P C^{T g 785}\right)$, and $P C^{--}\left(P C^{T g 527}\right)$ mice, the levels of plasma PC represents less than $1 \%, 1 \%, 3 \%$, and $18 \%$ of age- and gender-matched WT plasma respectively. (B) Survival of mixed-gender progenies derived from various $P C$ transgenic lines. The values in parentheses indicate the PC levels in the corresponding strains as percent of WT values. $P C^{--}\left(P C^{T g 535}\right)$ offspring $(n=46)$ had the poorest survival and the lowest $P C$ levels compared with progenies from $P C^{--}\left(P C^{T g 527}\right)(n=49), P C^{--}\left(P C^{T g 785}\right)(n=144)$, or $P C^{--}\left(P C^{T g 4}\right)$ $(n=63)$ strains. The disease onset and death in $P C^{-1}\left(P C^{T g 535}\right)$ littermates occurred at a young age ( $<1$ month). In contrast, offspring from $P C^{-/-}$ $\left(P C^{T g^{4}}\right)$ and $P C^{-1-}\left(P C^{T g 785}\right)$ mice had late-onset thrombotic phenotypes and accordingly longer survival. Progenies from $P C^{--}\left(P C^{T g 527}\right)$ mice lacked spontaneous phenotypes and developed normally.

became more hemorrhagic, as bleeding times were significantly prolonged (Figure $3 \mathrm{~K}$ ). These findings suggest that hemorrhage was a secondary event to thrombosis, i.e, consumptive coagulopathy was the underlying cause of their hemorrhagic phenotype. This finding was further strengthened by evidence of disseminated intravascular coagulation in 12-week-old mice, as indicated by a significant change in plasma D-dimer levels (data not shown).

Histological examination of the H\&E-stained sections revealed large thrombus deposits in various vessels and organs in $\mathrm{PC}^{-/-}$ $\left(P^{T g} 4\right)$ and $P C^{-1-}\left(P C^{T g} 785\right)$ transgenic mice at 4 months of age compared with WT littermates. Fibrinogen/fibrin deposits were frequently observed in the lung, heart, and liver (Figure 4, A-F). Enhanced leukocytic infiltration into lung alveoli was observed in $P^{-1-}\left(P^{T g} g^{4}\right)$ and $P C^{-1-}\left(P C^{T g 785}\right)$ transgenic mice compared with WT mice (Figure 4, G and $\mathrm{H}$ ). To examine whether enhanced leukocytic infiltration in the lung was a reaction to thrombus formation or a consequence of PC insufficiency, we assessed infiltration of leukocytes in mice at various ages. Total and differential cell counts were determined in bronchoalveolar lavage fluid (BALF) collected from mice at 4, 8, 12, and 16 weeks of age. Significant differences in lymphocyte counts were observed in low-PC mice compared with WT mice at 8 weeks of age. Furthermore, both lymphocyte and neutrophil counts increased with age in low-PC mice, while no differences in lymphocytes or neutrophils were observed in WT mice at various ages (Figure 4I). Given that 8-week-old low-PC mice showed signs of prothrombotic phenotypes, it is not fully clear whether leukocyte infiltration in mice of this age was promoted by enhanced thrombosis or by a severe PC deficiency. However, the finding that enhanced leukocytic infiltration advanced with age implies that lung inflammation is secondary to thrombosis in the older mice.

Spontaneous enhanced thrombosis was evident in $\mathrm{PC}^{-/-}$ $\left(P^{T g} 4\right)$ and $P C^{-1-}\left(P C^{T g 785}\right)$ mice, as indicated by increased plasma $\mathrm{D}$-dimer levels, which suggests enhanced fibrinolysis (Figure 5A). Accordingly, the thrombin-antithrombin (TAT) levels in these PC-insufficient mice were also significantly elevated, which suggests increased thrombin generation (Figure 5B), presumably due to loss of the ability to regulate FVa and FVIIIa by aPC. In addition, these increased plasma thrombin levels may account for the platelet activation observed in low-PC mice, as shown by flow cytometric analysis of P-selectin (P-Sel) expression on the surface of activated platelets (Figure 5C).

Prolonged activated partial thromboplastin times (aPTTs) (Figure 5D), but not prothrombin times, were noted in low-PC 

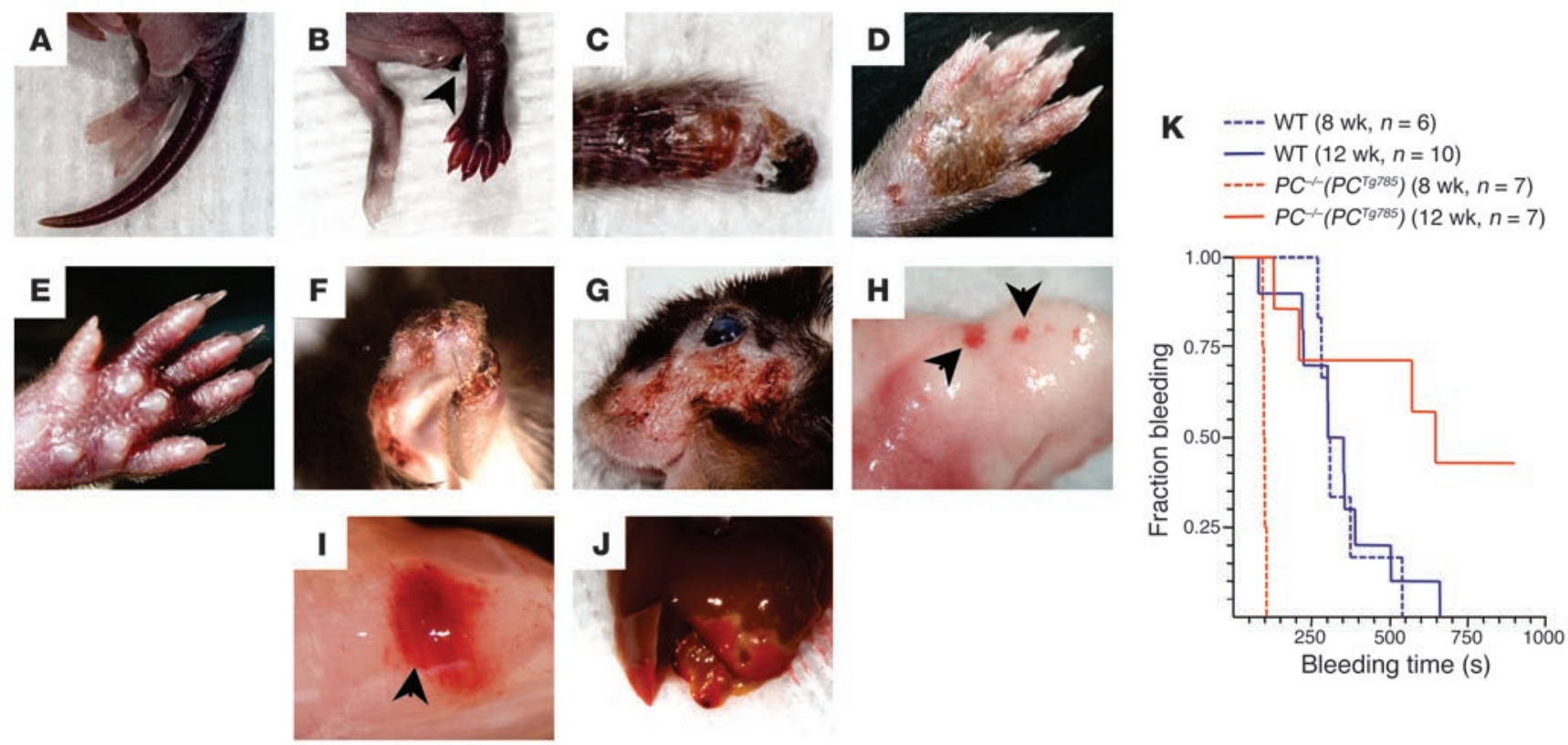

\section{Figure 3}

Gross phenotypes of the low-PC transgenic mice. (A and B) Early onset of severe hemorrhage in the tails and legs of $P C^{-1-}\left(P C^{T g 535}\right)$ littermates. $(\mathbf{C}-\mathbf{G})$ Late onset of thromboembolic phenotypes in $P C^{-1-}\left(P C^{T g 785}\right)$ and $P C^{--}\left(P C^{T g 4}\right)$ offspring characterized by hemorrhagic skin lesions affecting various parts of the body (C: tail; $\mathbf{D}$ and $\mathbf{E}$ : paws; $\mathbf{F}$ : ear; $\mathbf{G}$ : face). ( $\mathbf{H}$ and $\mathbf{I})$ Specimens collected from $P C^{-/-}\left(P C^{T g 785}\right)$ mice euthanized due to illness. Multiple focal hemorrhagic lesions in the lung $(\mathbf{H})$ and muscle $(\mathbf{I})$ of the legs. (J) Severe necrosis of regions of the liver. (K) Tail bleeding times were measured in $P C^{-/-}\left(P C^{T g 785}\right)$ mice of various ages. The data are expressed as the fraction still bleeding as a function of time. No statistical differences were found in bleeding times between 8- and 12-week-old WT mice. In contrast, low-PC mice at 8 weeks showed significantly shorter bleeding times compared with WT mice, while the 12-week-old low-PC mice had significantly prolonged bleeding times compared with 8-week-old low-PC or WT mice.

mice. Consumptive coagulopathy may account for the discernible reduction in the aPTTs, given the prothrombotic phenotypes observed. In addition, platelet levels were higher in $\mathrm{PC}^{-/-}\left(\mathrm{PC}^{\mathrm{Tg} 785}\right)$ mice than in WT mice (Figure 5E). Consistent with increased platelet production, spleens from these low-PC mice were consistently larger than those from WT mice of the same age and gender (low PC, $410 \pm 65.6 \mathrm{mg}$; WT, $110 \pm 36.1 \mathrm{mg} ; P<0.05$ ). H\&E stains confirmed the presence of increased numbers of megakaryocytes in the spleen. Megakaryocyte counts were also determined in bone marrows of these mice. Consistent with the increased spleen megakaryocyte population, the data showed that bone marrow megakaryocyte counts were higher in $\mathrm{PC}^{-1-}\left(\mathrm{PC}^{\mathrm{Tg} 785}\right)$ than in WT mice (low-PC, 6.68\%; WT, 2.44\%; $P<0.05$ ).

Low-PC transgenic mice develop proinflammatory phenotypes. Beyond its pivotal role in maintaining hemostasis, $\mathrm{PC}$ also exhibits a crucial function in directly or indirectly combating inflammatory challenges imposed on the host immune system (21). PC exerts its antiinflammatory function both by inhibiting thrombin generation and thus overriding downstream effects of the thrombin-induced proinflammatory response (22) and by signaling through EPCR in a PAR-1-dependent manner (23-25). PC also prevents inflammation by downregulating inflammatory signaling mediators, such as IL-6 (18, 26-28). Accordingly, various markers were measured to evaluate the resting inflammatory potential in these low-PC mice. Higher total wbc counts were observed in low-PC mice compared with WT mice, and granulocytes accounted for more than $40 \%$ of the total wbcs (Figure 5F). Moreover, an elevated unchallenged plasma level of
IL-6 (Figure 5G), but not TNF- $\alpha$ (data not shown), was seen in these $P C^{-1-}\left(P C^{T g 785}\right)$ mice.

We addressed the question of whether this basal hyperinflammatory state was due to an inflammatory effect of the PC deficiency or to the corresponding high thrombin levels by assessing the inflammatory state in $P C^{-1-}\left(P C^{T g 785}\right)$ mice after continual administration of hirudin to 12 -week-old mice for 3 days. Mice treated with hirudin have a significant reduction in plasma thrombin activity as indicated by a 4-fold increase in aPTT compared with that of controls, at day 3 after pump implantation. No side effects, e.g., bleeding, were associated with hirudin treatment over this time. Despite the substantial decrease in active thrombin levels, the inflammatory state of these mice remained unchanged; specifically, wbc counts and IL-6 (Figure 5, H-I) levels did not significantly decrease over the 3-day treatment. These unchanged inflammatory conditions implied that inflammation in low-PC mice was likely a thrombin-independent event. Moreover, direct determination of plasma leukotriene B4 in 4- to 8-week-old mice further suggested that low-PC mice have inflammation at ages 4 and 8 weeks (Figure $5 \mathrm{~J})$. These data suggest that PC deficiency promotes inflammation in the absence of obvious thrombosis.

Spontaneous abortion in very low-PC transgenic mothers. This study further shows that although low levels of PC had no impact on male or female fertility, a severe PC insufficiency inhibited the ability of females to sustain pregnancy to full term. To examine whether the potential cause of pregnancy failure was of maternal influence, or whether the $\mathrm{PC}^{-/-}$offspring determine the fatal course of pregnancy, breedings were established by mating $\mathrm{PC}^{-1-}\left(\mathrm{PC}^{\mathrm{Tg} 785}\right)$ 

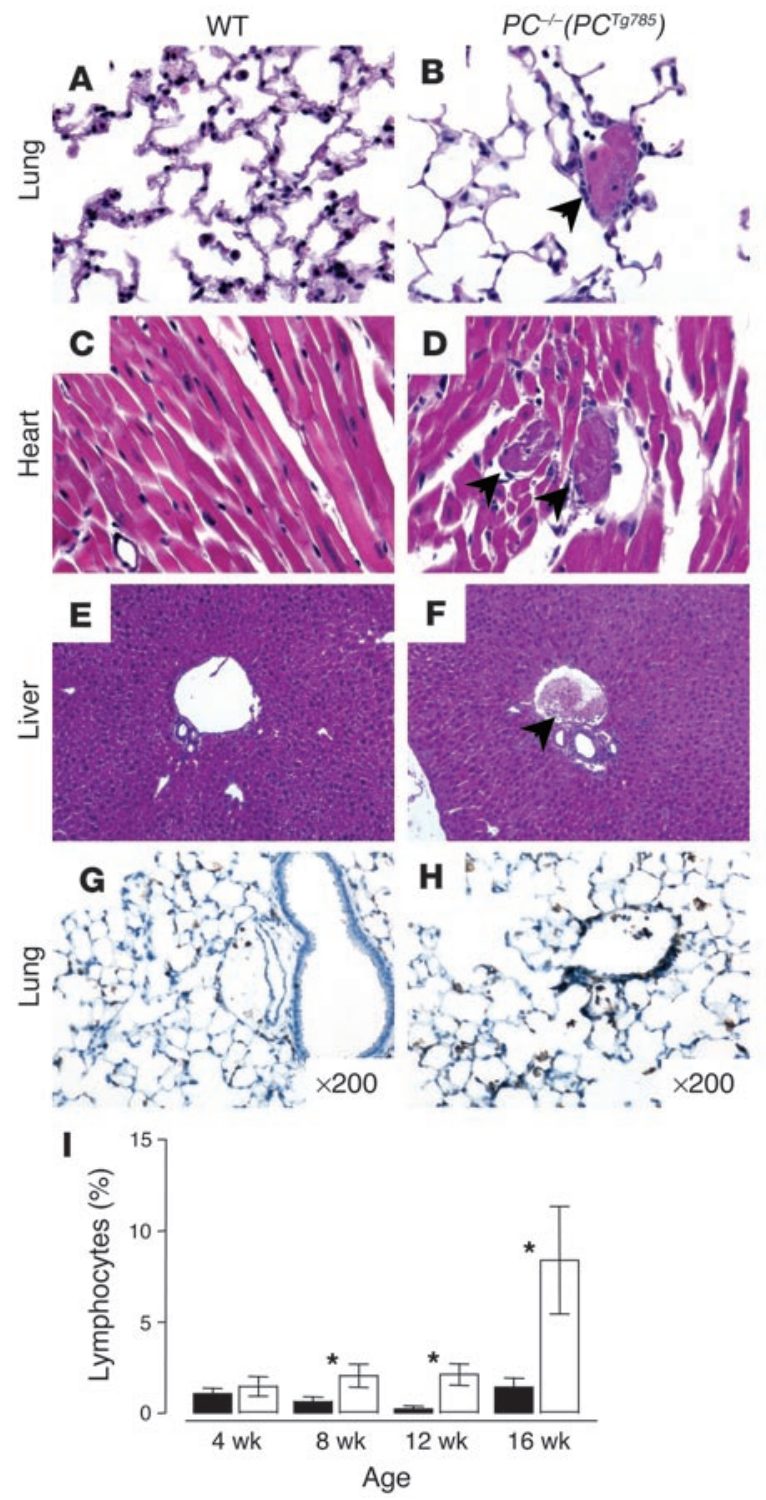

female mice with either $P C^{-/-}\left(P C^{T g 785}\right)$ or $P C^{+/+}\left(P C^{T g 785}\right)$ male mice to generate progenies of $100 \% \mathrm{PC}^{-/-}\left(\mathrm{PC}^{\text {Tg }}{ }^{785}\right)$ or $100 \% \mathrm{PC}^{+/-}\left(\mathrm{PC}^{\mathrm{Tg} 785}\right)$ mice, respectively. Neither of the matings led to full-term pregnancies. Spontaneous abortions affected all fetuses, regardless of the fetal PC genotypes. These findings strongly suggest that the underlying pathology of the pregnancy failure was strictly a maternal factor. Control breedings with $P C^{+/+}\left(P C^{T g 785}\right)$ females excluded the possibility that disruption of pregnancy-related gene(s) at the site of PC transgene integration played a role in the spontaneous abortions observed in these transgenic mice.

We established timed matings of $P C^{-1-}\left(P C^{T g 785}\right)$ females with $P^{-/-}\left(P C^{T g}{ }^{785}\right)$ or $P^{+/+}\left(P C^{T g 785}\right)$ males to determine the stages of embryonic lethality in low-PC mothers. Embryos retrieved from $P C^{-/-}\left(P C^{\operatorname{Tg} 785}\right)$ mothers at 6.5 days postcoitum $(\mathrm{dpc})$ appear to have normal developmental morphology. However, enhanced bleeding and fibrin deposition were noticeable at the ectoplacental cone region in low-PC mothers but were absent in WT mice (Figure 6, A and B). At this stage, embryonic development in low-PC and WT mothers was morphologically indistinguishable, and no evi-

\section{Figure 4}

Histological analyses of various tissues from $P C^{-/-}\left(P C^{T g 785}\right)$ mice. (A-D) Enhanced fibrin deposition in the $P C^{--}\left(P C^{T g 785}\right)$ mice compared with WT littermates was found in the lung and the heart (arrowheads). ( $\mathbf{E}$ and $\mathbf{F}$ ) A thrombus in the hepatic vessel. ( $\mathbf{G}$ and $\mathbf{H}$ ) Anti-CD45 immunostaining revealed increased leukocyte infiltration into the alveolar space and the adjacent vein of the lung in low-PC mice. (I) Lymphocyte counts in BALF from mice at various ages. Black bars, WT mice; white bars, $P C^{--}\left(P C^{T g 785}\right)$ mice. ${ }^{*} P<0.05$ between genotypes.

dence of trophoblast giant cell death was associated with embryos derived from $P C^{-/-}\left(P C^{\operatorname{Tg} 785}\right)$ mothers. Staining for proliferating cell nuclear antigen (PCNA) indicated ongoing active proliferation (data not shown). However, at $7.5 \mathrm{dpc}$, multiple hemorrhage and extensive fibrin deposition were enhanced in the low-PC mothers (Figure 6, C and D). Embryonic growth was restricted, and TUNEL assays revealed extensive trophoblast giant cell death in all embryos derived from $P C^{-/-}\left(P C^{T g 785}\right)$ mothers (Figure 6, E and F). By $8.5 \mathrm{dpc}$, most embryos were either growth retarded or in advanced stages of resorption (Figure 6, G and H).

To gain additional insight into the cause of these failed pregnancies, we explored whether enhanced thrombosis was partly responsible for spontaneous abortion, employing females from the 4 low-PC transgenic lines generated in this study. It was found that only the $P C^{-/-}\left(P C^{T 5527}\right)$ transgenic females could sustain pregnancy and deliver healthy pups. The fact that fetal development was normal through $5.5 \mathrm{dpc}$ in all lines implied that blastocyst development prior to implantation is not PC dependent. This observation supports the concept that maternal plasma PC is needed to sustain embryonic development, likely by regulating the extent of bleeding associated with endometrial remodeling during trophoblast implantation.

We examined whether not only enhanced thrombosis but also preexisting maternal inflammation contributed to pregnancy loss in $P^{-/-}\left(P C^{T 7785}\right)$ mothers. Consistent with their proinflammatory phenotypes, recruitment of leukocytes to the ectoplacental cone region at $7.5 \mathrm{dpc}$ was markedly enhanced in low-PC mice, suggestive of an inflammatory response at the implantation site (Figure 6, I and J).

The finding that resting low-PC mice displayed a baseline proinflammatory condition raised the question of whether enhanced inflammation contributes to the spontaneous abortion in the low-PC mothers. To examine whether normal pregnancies in $P C^{-/-}\left(P C^{T 5527}\right)$ mice were the result of reduced maternal inflammation, we compared the thrombotic and inflammatory responses of $\mathrm{PC}^{-/-}\left(\mathrm{PC}^{\mathrm{Tg} 785}\right)$ and $\mathrm{PC}^{-/-}\left(\mathrm{PC}^{\mathrm{Tg} 527}\right)$ mice. Consistent with their lack of spontaneous thrombosis, $P C^{-/-}\left(P C^{\text {Tg527 }}\right)$ mice did not show evidence of an inflammatory response. Granulocyte counts were comparable to those of WT mice (Figure 5F). Additionally, plasma D-dimer and TAT levels in $P C^{-/-}\left(P C^{\text {Tg527 }}\right)$ mice were indistinguishable from those same values in WT mice (Figure 5, A and B) but significantly lower than the levels found in mice derived from the $P C^{-/-}\left(P C^{T g 785}\right)$ transgenic line. Similarly, unlike in $\mathrm{PC}^{-/-}\left(\mathrm{PC}^{\operatorname{Tg} 785}\right)$ transgenic mice, IL-6 was undetectable in $P C^{-/-}\left(P C^{\text {Tg }}{ }^{527}\right)$ mice (data not shown). These findings together indicate a lack of spontaneous inflammation in $\mathrm{PC}^{-/-}\left(\mathrm{PC}^{\text {Tg527}}\right)$ mice, the mouse strain expressing the highest levels of PC.

Rescue of embryonic lethality in PC-insufficient mothers. While it seems very clear that maternal PC is necessary to maintain pregnancies, we rigorously examined this concept using an ovarian transplant strategy. Ovaries from $\mathrm{PC}^{-/-}\left(\mathrm{PC}^{\mathrm{Tg} 785}\right)$ females were transplanted 

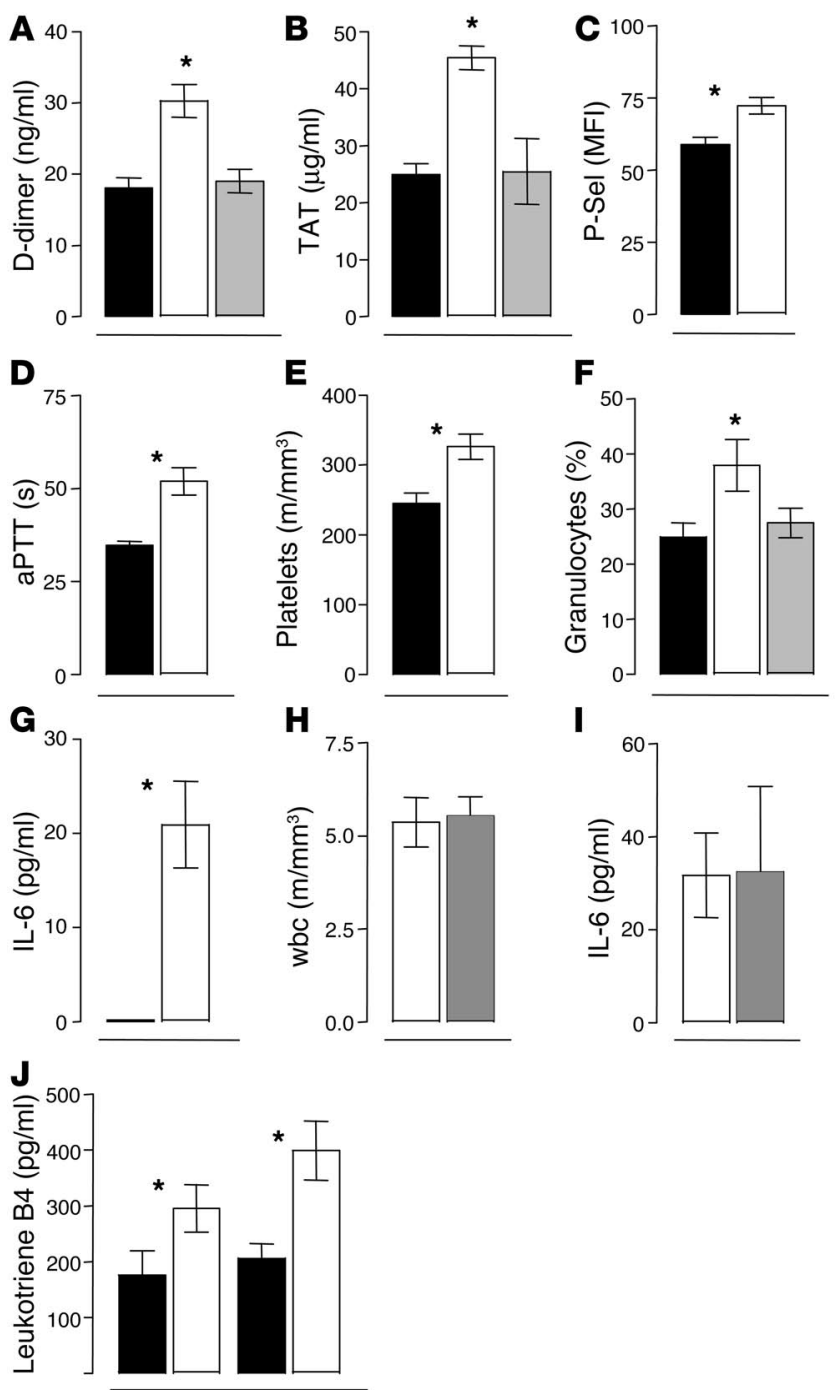

into WT mothers, and the recipient females were mated with $P C^{-/-}\left(P C^{T g 785}\right)$ males. From 7 recipients, 35 pups were born, all of which were genetically $P C^{-1-}\left(P C^{T g 785}\right)$. As described above, no births occurred when $P C^{-1-}\left(P C^{T g 785}\right)$ biological mothers were mated with males of any PC genotype or when WT mouse ovaries were transplanted into genetic $P C^{-/-}\left(P C^{T g 785}\right)$ females. Since a very small portion of WT ovary tissue was allowed to remain in the transplanted female to assist revascularization with transplanted tissue, it is possible that pups could occasionally have been born with a WT allele, although this would be statistically rare. This did not occur in the breedings that are reported here, and all pups were born from $P C^{-/-}\left(P^{T g}{ }^{785}\right)$ ova, which would have been expected to heavily predominate. These experiments show that a restoration of maternal PC rescues embryonic development that is otherwise lethal beyond $7.5 \mathrm{dpc}$ in mothers with severe deficiency in PC. Thus, it is further confirmed that maternal $\mathrm{PC}$ is required to sustained pregnancy beyond $7.5 \mathrm{dpc}$.

\section{Discussion}

The findings from the present investigation provide a novel approach for the generation of various transgenic mouse lines expressing low levels of plasma PC. A previous study based on mat-

\section{Figure 5}

Detection of various prothrombotic and proinflammatory markers in plasma of female low-PC mice. Levels of plasma D-dimer (A), TAT (B), and P-Sel (expressed as mean fluorescence intensity [MFI]) (C), aPTT (D), platelet counts (E), granulocyte counts (F), and IL-6 levels $(\mathbf{G})$ in unchallenged female mice. Black bars, WT; white bars, $P C^{-/-}$

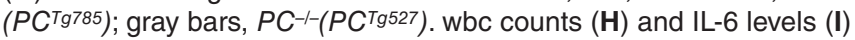
in $P C^{--}\left(P C^{T g 785}\right)$ mice following a 3-day treatment with saline (white bars) or hirudin (gray bars). (J) Leukotriene B4 in WT (black bars) and $P C^{-1-}\left(P C^{T g 785}\right)$ (white bars) mice. ${ }^{*} P<0.05$ between groups.

ings between $P C^{+/-}$parents indicated that $P C^{-/-}$embryos developed normally and were vaginally delivered but died early in the neonatal period (16). The postnatal lethality observed in $\mathrm{PC}^{-/-}$mice emphasized the critical importance of PC in hemostasis and survival. However, whether PC plays a role during embryonic development was not directly demonstrated. The fact that $\mathrm{PC}^{-/-}$embryos survived in utero implied that embryonic development is independent of a fetal supply of PC but could indicate that a small level of maternal transfer of PC to the embryo is sufficient for embryonic development (16). In apparent contrast to $\mathrm{PC}^{-/-}$mice, mice in which other genes of PC system components, e.g., TM (29) and EPCR (30), were deleted displayed an embryonically lethal phenotype. However, our current studies provided a unique opportunity to demonstrate that $\mathrm{PC}$ indeed has an important function during development and suggest that $\mathrm{PC}$ from the $\mathrm{PC}^{+/-}$mothers accounts for the survival of $\mathrm{PC}^{-/}$embryos during their development.

This study was designed to characterize mice with significantly reduced expression of PC in maternal plasma, such that PC-deficient mice would survive at the lowest possible PC levels. Humans with very low plasma concentrations of PC have been identified, which thus reinforces the need to develop an appropriate model to assess the function of PC during embryonic development. It is demonstrated here that in transgenic mice expressing $1 \%$ of WT plasma PC, the lethal phenotypes associated with a homozygous total PC deficiency are rescued. Using a cosmid-based approach, we have established 4 novel low-PC transgenic lines. The survival of these PC-insufficient mice was strongly correlated with the onset and progression of their spontaneous prothrombotic phenotypes. Mice derived from the $P C^{-1-}\left(P C^{T 5535}\right)$ transgenic line exhibited earlyonset of thrombosis and consequently had the poorest survival compared with offspring from transgenic lines expressing higher amounts of plasma PC. Severe depletion of PC in these transgenic mice predisposed them to thrombosis and proinflammatory conditions. The differences in survival and the severity of prothrombotic phenotypes observed in the $P C^{-/-}\left(P C^{\operatorname{Tg} 785}\right)$ and $P C^{-/-}\left(P C^{\operatorname{Tg} 527}\right)$ mouse lines strongly demonstrated that the underlying pathology of disease progression was PC dependent. In addition, the spontaneous and progressive thrombotic phenotypes noted in low-PC mice were similar to phenotypes observed in EC-specific TM-deficient mice (31), which thus reinforces the anticoagulant and antiinflammatory roles of the TM-PC system.

This study provides what we believe to be the first direct evidence that maternal PC is critical for sustaining embryonic development in mice beyond $7.5 \mathrm{dpc}$. The intricate mechanisms underlying the causes of death in $T M^{--}$embryos have been illustrated. Unfettered coagulation due to a TM deficiency led to trophoblast cell apoptosis at the feto-maternal interface (32). The mechanisms of trophoblast apoptosis occurring in low-PC mothers are expected to be similar to those in $T M^{-/-}$mice. These 
studies, combined with the observations that aPC/EPCR-PAR signaling regulates trophoblast cell growth (32), reinforce the importance of intact anticoagulation system components functioning together to maintain a successful pregnancy. Central to embryonic survival is the ability of trophoblast giant cells to generate aPC from maternal PC. Thus, a lack of maternal aPC, due either to a TM deficiency or low maternal PC levels, promotes trophoblast cell death. Additionally, interference of aPC/EPCRPAR signaling, either by total disruption of embryonic EPCR or from a lack of aPC, halts trophoblast development.

The presence of fibrin in the fibrinoid layer at the feto-maternal interface is necessary for stabilizing placental attachment (33). Fibrin degradation products also promote trophoblast cell apoptosis $(32,34)$. These findings suggest that the amount of fibrin present in the ectoplacental cone region must be tightly regulated for proper placental anchorage, while limiting trophoblast apoptosis. Although we demonstrate that enhanced coagulation/inflammation led to spontaneous abortion, it remains to be elucidated whether inflammatory cells present at sites of fibrin deposits could potentially promote trophoblast giant cell death and cause placental defects in low-PC mothers.

Our findings not only clearly reveal that maternal PC is required to sustain pregnancy but also show that a specific threshold of $\mathrm{PC}$ is necessary for maintaining pregnancy beyond $7.5 \mathrm{dpc}$. The various low-PC mouse lines, expressing PC below and above this threshold level, thus provide unique models to elucidate the role of maternal PC during embryonic development. Moreover, these data corroborate our hypothesis that escalated coagulation/inflammation is the pathology underlying pregnancy loss observed in mice with very low levels of PC.

Because pregnancy is recognized as a state of increasing maternal inflammation with advancing gestation (35), any preexisting inflammation may intensify this effect. We have shown that mice with levels of PC that are 4\% those of WT are in a preexisting inflammatory state, and these mice subsequently failed to maintain pregnancy. Consistent with our hypothesis that PC is critical in maintaining hemostasis/inflammation during pregnancy, it was shown that very low levels of LPS induced inflammation or preeclampsia-like syndrome in pregnant rats (36). Multiple data sources thus suggest that inflammation exists in pregnancy and that LPS exaggerates the response, perhaps due to a LPS-induced decrease in PC levels. These results, together with ours, provide support for a novel role of maternal PC in protection against excessive inflammation during pregnancy.

\section{Figure 6}

Spontaneous abortion in $P C^{-1-}\left(P C^{T g 785}\right)$ mothers. (A and B) H\&E stains of embryos in utero showing enhanced bleeding and fibrin deposition at the ectoplacental cone region and area surrounding a 6.5-dpc embryo. $(\mathbf{C}$ and $\mathbf{D})$ Intense fibrin depositions were present in 7.5-dpc embryos in $P C^{--}\left(P C^{T g 785}\right)$ mothers. However, proliferation of trophoblast giant cells remained comparable to that in WT mice (data not shown). (E and $\mathbf{F}$ ) Immunohistochemical staining using the TUNEL assay revealed extensive trophoblast giant cell death in $P C^{--}\left(P C^{T g 785}\right)$ mothers. H\&E staining of WT (G) and low-PC (H) 8.5-dpc embryos highlighting severe growth retardation and partially resorbed embryos accompanied by severe uterine bleeding in $P C^{-/}\left(P C^{T g 785}\right)$ mothers. (I and $\mathbf{J}$ ) Enhanced inflammation at the ectoplacental cone region as illustrated by increased antiCD45 positive leukocyte infiltration in $P C^{--}\left(P C^{T g 785}\right)$ compared with WT mothers. Asterisks indicate ectoplacental cone region.
The finding that the transgenic mouse lines established in our study exhibit enhanced thrombosis and inflammation resulting in spontaneous abortion presents a model for PC-associated thrombophilia in pregnancy. Congenital or acquired thrombophilia has been associated with pathophysiological processes underlying miscarriage, intrauterine growth restriction, and preeclampsia (37, 38). Preeclampsia represents an exaggerated form of a maternal intravascular inflammatory response, as well as abnormalities in the hemostatic system $(35,39)$. Studies have shown that an excessive maternal inflammatory response and defective placental development due to inadequate trophoblast invasion contribute to the pathogenesis of preeclampsia $(40,41)$. The findings that a PC insufficiency is associated with exaggerated maternal inflammation and placental defects are likely to be relevant to the clinical syndrome of thrombophilia-related pregnancy complications, e.g., preeclampsia, which suggests a potential role for PC in preeclampsia.

The establishment of these low-PC mice provides novel animal models for investigating various coagulation/inflammation-based pathologies involving the PC system. Further, an understanding
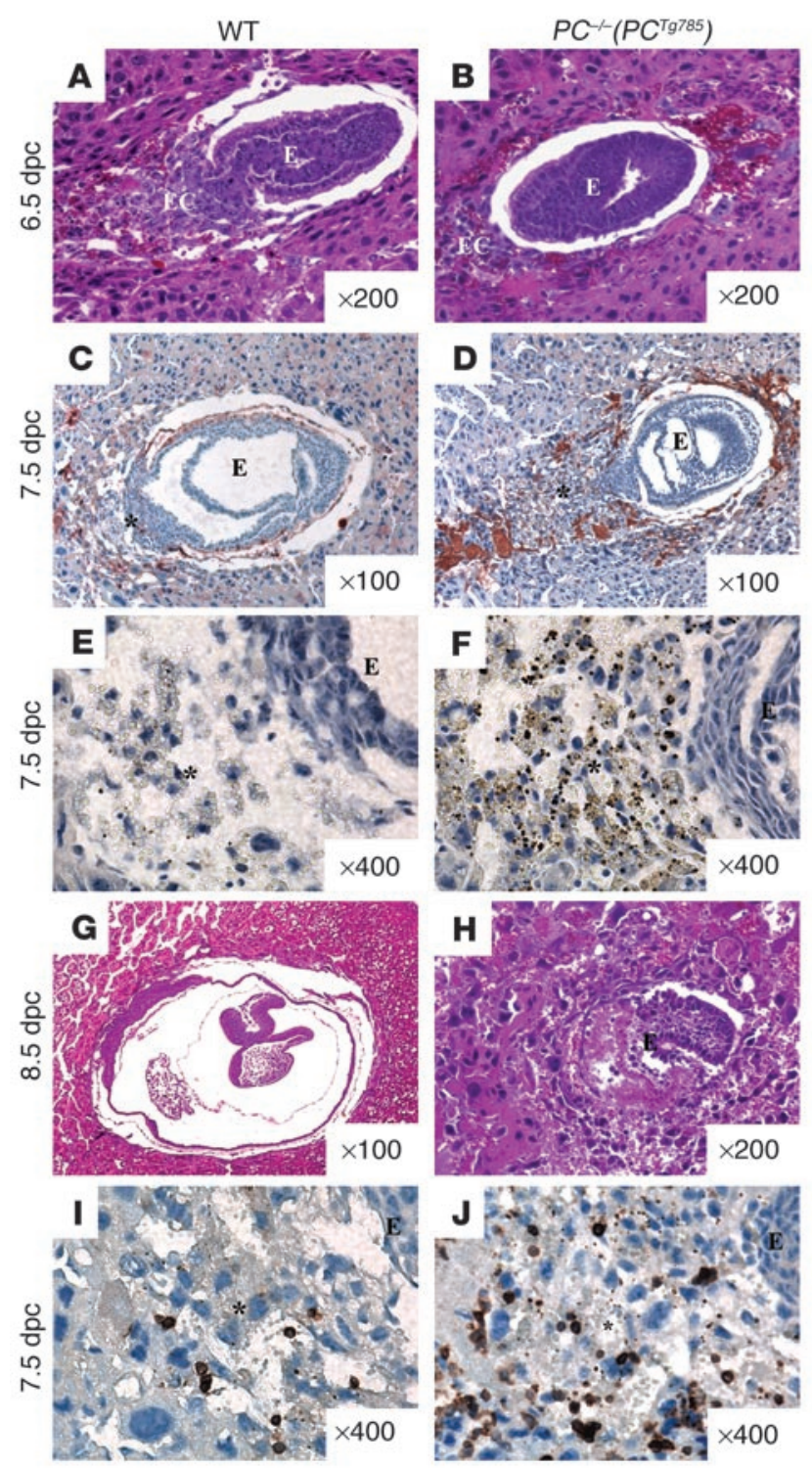
that a threshold level of maternal PC is critical to sustaining a successful pregnancy may lead to identification of a potential target for drug therapy in certain pregnancy disorders. Since recombinant aPC has been used for treatment of sepsis $(21,42,43)$ and in the management of spontaneous abortion in $\mathrm{PC}^{+/-}$patients $(44,45)$, studies with this low-PC model could add significantly to an understanding of the role of PC in certain pregnancy complications.

\section{Methods}

Generation of the PC cosmid-based construct. An EcoRI-BamHI fragment containing the complete mPC cDNA was excised from a plasmid (pIRESNeo$\mathrm{mPC}$ ) developed in our laboratory, purified, and treated with DNA polymerase and dNTPs to generate blunt ends. The fragment was cloned into the NruI site of another plasmid (pND586) developed in our laboratory. The relevant features of the latter plasmid are, sequentially, an engineered NotI site positioned $5^{\prime}$ of the murine FVII gene (46); an inactivated murine FVII gene in which the $5^{\prime}$-proximal promoter (47) was disrupted via an engineered deletion; the remaining FVII gene; the FVII-FX intergenic region; a multiple cloning site containing AgeI, NruI, NheI and XhoI sites; and exons 2-9 of the $F X$ gene. Insertion of the PC cDNA into the NruI site of the multiple cloning site provided pND586/PC, containing the PC cDNA immediately downstream of the $F X$ promoter of pND586. A 300-bp $\mathrm{XbaI}$-Xhol fragment containing the SV40 polyA sequence was excised from pIRESNeo and ligated into NheI-XhoI sites of PND586/PC, immediately $3^{\prime}$ of the mPC cDNA. This resulted in $\mathrm{pND} 586 / \mathrm{PC} / \mathrm{pA}$, which was used to construct the cosmid vector to generate the $P C$ transgene.

We derived the cosmid vector, pNDcosI, from superCosI (Stratagene) by modifying the multiple cloning site to contain unique NotI and SacII sites. The transgene cosmid vector was assembled in 4-way ligation of: (a) a XbaI-NotI fragment containing 1 Cos site of pNDcosI; (b) a XbaI-SacII fragment containing the second Cos site of pNDcosI; (c) a 15.3-kb NotIXhoI fragment derived from the plasmid, pND586/PC/pA; and (d) an 18 -kb XhoI-SacII fragment derived from a subclone of the mouse $F X$ gene containing exons 2-9, thus also inactivating the $F X$ gene in the final construct. Following ligation of the 4 fragments, the products were packaged using a $\lambda$ packaging mix (Stratagene) and used to infect permissive bacterial strain XL-Blue (Stratagene). DNA was isolated from ampicillin-resistant colonies to detect the transgene cosmid vector. Since the 4-fragment ligation can only assemble in 1 way to produce a molecule that can be packaged into a phage particle, and the efficiency of infection is high, the process consistently results in the planned cosmid.

Generation of low-PC transgenic mice. The 33.3-kb linearized fragment of the cosmid DNA containing the PC cDNA was microinjected into pronuclei of fertilized mouse embryos from strain C57BL/6. The microinjected embryos were then implanted into the oviducts of pseudopregnant female mice to generate $P C$ transgenic founders. Breeding of positive founders with $P C^{+/-}$mice led to the production of $P C^{+/-}\left(P C^{T g}\right)$ mice. Further mating with $P^{+/-}$mice generated offspring with a total inactivation of both WT $P C$ alleles but containing the $P C$ transgene or $P C^{-1-}\left(P C^{T g}\right)$. The care and use of all experimental animals were approved by the Institutional Animal Care and Use Committee of the University of Notre Dame.

Detection of the PC transgene. Genotyping of mice was accomplished by PCR. Forward and reverse primers located in exons 4 and 6 of PC, respectively, were used to amplify genomic DNA. These primers amplified a 497-bp WT fragment and a 284-bp fragment of PC transgene cDNA fragment. $P C^{+/}, P C^{+/}$, or $P C^{-/-}$genotypes were determined using a LightCycler system (Roche Diagnostics Corp.). A common PC sense primer, i.e., 5'-CGTGATGAGTTTCAGGCAGTGAGAG-3', in combination with the $\mathrm{PC}^{+/+}$antisense primer, $5^{\prime}$-GCACACGTGTTGACCAGGGATAAT- $3^{\prime}$, and the $P C^{-/-}$antisense primer, $5^{\prime}$-ACAAGCAAAACCAAATTAAGGGCCA-3', were used. The $P C^{+/+}$FITC/Red 640-labeled probes were: 5'-CTGCTTCTGCCTCTCGAGTACTAGCTCT-FITC-3' and $5^{\prime}$-Texas red-AGGGGTATGCCATCATGGCT-P-3', respectively. The $P \mathrm{C}^{-/-}$FITC/705-labeled probes were 5'-TGCTGATCTCGTTCTTCAGGCTAT-FITC-3' and 5' -Cy5.5-AACTGACACATTGGAAACCACAGTACTTAGAACCAC-P-3', respectively. For the mPC cDNA, the primers were 5'-GTGGAAGACACACTGGCCTTCTG-3' and 5'-GGTCGTCTGCCAGCTCATAG-3'. The probes used were 5'CACCCGACAGTCCTGGAAGCGCAA-FITC-3' and 5'-Cy5.5-CCTGCTGACAGAACTTGCCCTCCC-P-3'

Detection of $P C$ transgene integration using Southern blot analysis. We determined the patterns of $P C$ transgene integration using KpnI-digested genomic DNA. The approximately 500-bp probe was a PCR amplicon of a sequence contained entirely within exon 1 of the FVII gene and was labeled with $\alpha-\left[{ }^{32} \mathrm{P}\right] \mathrm{dCTP}$. Hybridization resulted in a $2.7-\mathrm{kb}$ band representing endogenous FVII (Figure 1A) in addition to various bands (X; Figure $1 \mathrm{~A}$ ) of the PC cDNA transgene that are dependent on sites of transgene integration.

Measurement of plasma PC antigen levels. We measured the plasma PC antigenic level using a specific ELISA for mPC. A volume of $100 \mu \mathrm{l}$ of $5 \mu \mathrm{g} / \mathrm{ml}$ of an in-house chicken anti-mPC polyclonal antibody (AJL2) was adsorbed to microtiter plates and used as the capture antibody. After washing, $100 \mu \mathrm{l}$ of plasma from low-PC or WT mice was added to immobilize the component PC. The bound PC was detected with an in-house rabbit anti-mPC polyclonal antibody (AJL1), followed by goat anti-rabbit alkaline phosphatase-conjugated IgG. The complex was assayed with the substrate $p$-nitrophenylphosphate (Sigma-Aldrich), and the liberation of $p$-nitroanilide from this substrate was determined by absorbance measurements at $405 \mathrm{~nm}$ and $490 \mathrm{~nm}$.

Detection of various plasma proteins and coagulation factor activities. Plasma IL-6 and leukotriene B4 were assayed using commercial ELISA kits (R\&D Systems). The D-dimer ELISA kit and reagents for aPTT were purchased from DIAGNOSTICA STAGO Inc., and antibodies for TAT ELISA determinations were obtained from Enzyme Research Laboratories. Granulocyte, $w b c$, and platelet counts were determined using the VetScan analyzer (ABAXIS Inc.). We assessed circulating activated platelets by flow cytometry analysis using an EPICS-XL Flow Cytometer (Beckman Coulter). For this, approximately $500 \mu \mathrm{l}$ of whole blood was carefully withdrawn from the inferior vena cava of anesthetized mice $(n=6)$. We assessed platelet activation by measuring the level of P-Sel expression on the platelet surface using CD62P antibody (BD Biosciences - Pharmingen).

Hirudin treatment. Twelve-week-old $P C^{-1-}\left(P C^{T g 785}\right)$ mice $(n=9)$ were treated with $100 \mu \mathrm{l}$ of the thrombin inhibitor hirudin at a concentration of 25 $\mu \mathrm{g} / \mu \mathrm{l}$ or with saline. Hirudin or saline was administered via osmotic pumps (DURECT Corp.) implanted intraperitoneally for 3 days. We assessed plasma levels of active thrombin by determining the aPTT values at day 3 . Accordingly, various inflammatory markers were measured in whole blood and in plasma of mice treated with hirudin compared with saline.

Histology/immunobistochemistry. Sections $(4 \mu \mathrm{m})$ were prepared from periodate-lysine-paraformaldehyde-fixed, paraffin-embedded tissues. Slides were stained with $\mathrm{H} \& \mathrm{E}$ or specific immunohistochemical stains for fibrinogen (Accurate Chemical \& Scientific Corp.), PCNA (BioGenex), TUNEL (Invitrogen Corp.), and rat anti-mouse CD45 (BD Biosciences - Pharmingen).

Tail bleeding times. Tail bleeding times were assessed by standard procedures on WT and low-PC mice at 4, 8, and 12 weeks of age. We anesthetized the subject mice using rodent cocktail, and an approximately a 3-mm tail tip was cut to expose the artery and veins. The excised end was then immersed in a test tube containing saline solution prewarmed to $37^{\circ} \mathrm{C}$. Bleeding was monitored visually and the time taken until bleeding ended was recorded. 
Megakaryocytes in bone marrow. Bone marrow aspirates were collected from both femurs of each mouse $(n=6)$ in saline solution. The cells were centrifuged at 1,200 rpm for 5 minutes and resuspended in $200 \mu \mathrm{l}$ of PBS containing $1 \%$ BSA. Bone marrow differential cell counts were determined on smear preparations stained with Diff-Quick solution (IMEB Inc.). A total of 500 cells were counted, and megakaryocyte populations were expressed as the percentage of total cells.

$B A L F$ collection. We prepared BALF by infusing 3 aliquots of $500 \mu \mathrm{l}$ sterile PBS into the lung. Following collection, BALF was centrifuged at $1,200 \mathrm{rpm}$ for 10 minutes and resuspended in $500 \mu \mathrm{l}$ of PBS/1\% BSA. BALF differential cell counts were determined on cytospin preparations stained with Diff-Quick.

Ovary transplantations. Both donor and recipient females were anesthetized with rodent cocktail. A sterile incision was made in the middle of the back of the donor and the ovaries and uterus extracted from the body. Using fine dissection scissors, we made a small incision in the bursa on the side opposite the opening of the oviduct and removed the ovaries by dissection, leaving a small amount of ovary tissue in the mouse. The donor was then sacrificed by overdose of isoflurane, followed by cervical dislocation. The ovaries were placed in culture medium (DMEM/10\% FBS) for a short period of time while the recipient mouse was prepared.

One ovary and uterus of the recipient mouse was extracted from the body as described above. The incision made was no larger than needed to remove the ovary of the recipient so that the bursa was left mostly intact. A drop of diluted epinephrine was placed on the bursa to reduce bleeding. The donor ovary was then inserted into the bursal sac and the ovary and uterus placed back into the animal. The oviduct on the opposite side was ligated with a suture and returned to the body cav-

1. Dahlback, B. 2004. Progress in the understanding of the protein $\mathrm{C}$ anticoagulant pathway. Int.J. Hematol. 79:109-116.

2. Esmon, N.L., Owen, W.G., and Esmon, C.T. 1982. Isolation of a membrane-bound cofactor for thrombin-catalyzed activation of protein C. J. Biol. Chem. 257:859-864.

3. Taylor, F.B., Peer, G.T., Lockhart, M.S., Ferrell, G., and Esmon, C.T. 2001. Endothelial cell protein C receptor plays an important role in protein $\mathrm{C}$ activation in vivo. Blood. 97:1685-1688.

4. Kisiel, W., Canfield, W.M., Ericsson, L.H., and Davie, E.W. 1977. Anticoagulant properties of bovine plasma protein $\mathrm{C}$ following activation by thrombin. Biochemistry. 16:5824-5831.

5. Vehar, G.A., and Davie, E.W. 1980. Preparation and properties of bovine factor VIII (antihemophilic factor). Biochemistry. 19:401-410.

6. D’Angelo, A., Lockhart, M.S., D'Angelo, S.V., and Taylor, F.B. 1987. Protein S is a cofactor for activated protein $C$ neutralization of an inhibitor of plasminogen activation released from platelets. Blood. 69:231-237.

7. Melissari, E., and Kakkar, V.V. 1989. Congenital severe protein C deficiency in adults. Br. J. Haematol. 72:222-228.

8. Sternberg, T.L., Bailey, M.K., Lazarchick, J., and Brahen, N.H. 1991. Protein C deficiency as a cause of pulmonary embolism in the perioperative period. Anesthesiology. 74:364-366.

9. Muller, F.M., Ehrenthal, W., Hafner, G., and Schranz, D. 1996. Purpura fulminans in severe congenital protein $\mathrm{C}$ deficiency: monitoring of treatment with protein C concentrate. Eur. J. Pediatr. 155:20-25.

10. Kohler, J., Kasper, J., Witt, I., and von Reutern, G.M. 1990. Ischemic stroke due to protein C deficiency. Stroke. 21:1077-1080.

11. Martinez-Ferrer, J., et al. 1990. Severe pulmonary arterial hypertension caused by protein $\mathrm{C}$ deficiency reversible after medical treatment [in Spanish].

ity. This procedure ensured that there was a hormonally functioning ovary in place, but its ova could not be fertilized. The mouse was then placed in a cage on a warming area and allowed to recover for 3 weeks prior to mating. Approximately 40 mice were implanted in this manner. Two anesthesia-related deaths were observed, and all surviving females to date have reproduced.

Statistical analysis. All data are expressed as mean \pm SEM, unless otherwise indicated. Comparisons between groups were conducted using the paired Student's $t$ test. The log-rank test was used to compare survival curves (Kaplan-Meier curves). $P<0.05$ was considered statistically significant.

\section{Acknowledgments}

We thank John Griffin (Scripps Research Institute) for the gift of the mPC-expressing heterologous cell line, Andrew Martin and Juan Fu for RNA analysis, Mayra Sandoval-Cooper and Maeve Bonner for histology assistance, and Debbie Donahue for bone marrow collection/ovarian transplant surgeries. A.J. Lay is a Walther Cancer Institute Postdoctoral Fellow. The study was supported by NIH grants HL019982 and HL073750 (to F.J. Castellino).

Received for publication November 29, 2004, and accepted in revised form March 29, 2005.

Address correspondence to: Francis J. Castellino, W.M. Keck Center for Transgene Research, 434 Stepan Hall of Chemistry \& Biochemistry, University of Notre Dame, Notre Dame, Indiana 46556, USA. Phone: (574) 631-9152; Fax: (574) 631-8017; E-mail: fcastell@nd.edu.

Rev. Esp. Cardiol. 43:195-197.

12. Esmon, C.T. 2002. New mechanisms for vascular control of inflammation mediated by natural anticoagulant proteins. J. Exp. Med. 196:561-564.

13. Esmon, C.T. 2002. Protein C pathway in sepsis. Ann. Med. 34:598-605.

14. Esmon, C.T. 2003. Coagulation and inflammation. J. Endotoxin Res. 9:192-198.

15. Haley, M., et al. 2004. Activated protein C in sepsis: emerging insights regarding its mechanism of action and clinical effectiveness. Curr. Opin. Infect. Dis. 17:205-211.

16. Jalbert, L.R., et al. 1998. Inactivation of the gene for anticoagulant protein $\mathrm{C}$ causes lethal perinatal consumptive coagulopathy in mice. J. Clin. Invest. 102:1481-1488.

17. Levi, M., et al. 2003. Aggravation of endotoxininduced disseminated intravascular coagulation and cytokine activation in heterozygous protein C-deficient mice. Blood. 101:4823-4827.

18. Ganopolsky, J.G., and Castellino, F.J. 2004. A protein $\mathrm{C}$ deficiency exacerbates inflammatory and hypotensive responses in mice during polymicrobial sepsis in a cecal ligation and puncture model. Am. J. Pathol. 165:1433-1446.

19. Liang, Z., Cooper, A., Rosen, E.D., and Castellino, F.J. 1998. Chromosomal arrangement of the murine coagulation factor VII and factor X genes. Thromb. Haemost. 80:524-525.

20. Wilberding, J.A., and Castellino, F.J. 2000. Characterization of the murine coagulation factor $\mathrm{X}$ promoter. Thromb. Haemost. 84:1031-1038.

21. Bernard, G.R., et al. 2001. Efficacy and safety of recombinant human activated protein $\mathrm{C}$ for severe sepsis. N. Engl. J. Med. 344:699-709.

22. Van de Wouwer, M., Collen, D., and Conway, E.M. 2004. Thrombomodulin-protein C-EPCR system: integrated to regulate coagulation and inflammation. Arterioscler. Thromb. Vasc. Biol. 24:1374-1383.

23. Riewald, M., Petrovan, R.J., Donner, A., Mueller, B.M., and Ruf, W. 2002. Activation of endothelial cell protease activated receptor 1 by the protein C pathway. Science. 296:1880-1882.

24. Cheng, T., et al. 2003. Activated protein C blocks p53-mediated apoptosis in ischemic human brain endothelium and protects in a murine stroke model through EPCR and PAR-1. Nat. Med. 9:258-260.

25. Ruf, W., Dorfleutner, A., and Riewald, M. 2003. Specificity of coagulation factor signaling. J. Thromb. Haemost. 1:1495-1503.

26. Schmidt-Supprian, M., et al. 2000. Activated protein $\mathrm{C}$ inhibits tumor necrosis factor and macrophage migration inhibitory factor production in monocytes. Eur. Cytokine Netw. 11:407-413.

27. Joyce, D.E., and Grinnell, B.W. 2002. Recombinant human activated protein $C$ attenuates the inflammatory response in endothelium and monocytes by modulating nuclear factor-kappaB [review]. Crit. Care Med. 30(Suppl. 5):S288-S293.

28. Brueckmann, M., et al. 2004. Activated protein C inhibits the release of macrophage inflammatory protein-1-alpha from THP-1 cells and from human monocytes. Cytokine. 26:106-113.

29. Healy, A.M., Rayburn, H.B., Rosenberg, R.D., and Weiler, H. 1995. Absence of the blood-clotting regulator thrombomodulin causes embryonic lethality in mice before development of a functional cardiovascular system. Proc. Natl. Acad. Sci. U. S. A. 92:850-854.

30. Gu, J.M., et al. 2002. Disruption of the endothelial cell protein $\mathrm{C}$ receptor gene in mice causes placental thrombosis and early embryonic lethality. J. Biol. Chem. 277:43335-43343.

31. Isermann, B., et al. 2001. Endothelium-specific loss of murine thrombomodulin disrupts the protein $\mathrm{C}$ anticoagulant pathway and causes juvenile-onset thrombosis. J. Clin. Invest. 108:537-546. doi:10.1172/JCI200113077.

32. Isermann, B., et al. 2003. The thrombomodulinprotein $\mathrm{C}$ system is essential for the maintenance of pregnancy. Nat. Med. 9:331-337.

33. Iwaki, T., et al. 2002. Fibrinogen stabilizes placen- 
tal-maternal attachment during embryonic development in the mouse. Am. J. Pathol. 160:1021-1034.

34. Ratts, V.S., et al. 2000. Expression of BCL-2, BAX and $\mathrm{BAK}$ in the trophoblast layer of the term human placenta: a unique model of apoptosis within a syncytium. Placenta. 21:361-366.

35. Redman, C.W., and Sargent, I.L. 2003. Preeclampsia, the placenta and the maternal systemic inflammatory response - a review. Placenta. 24(Suppl. A):S21-S27.

36. Faas, M.M., Schuiling, G.A., Baller, J.F., Visscher, C.A., and Bakker, W.W. 1994. A new animal model for human preeclampsia: ultra-low-dose endotoxin infusion in pregnant rats. Am. J. Obstet. Gynecol. 171:158-164.

37. Greer, I.A. 2003. Thrombophilia: implications for pregnancy outcome [review]. Thromb. Res. 109:73-81.

38. Rasmussen, A., and Ravn, P. 2004. High frequency of congenital thrombophilia in women with path- ological pregnancies? Acta Obstet. Gynecol. Scand. 83:808-817.

39. van Pampus, M.G., et al. 1999. High prevalence of hemostatic abnormalities in women with a history of severe preeclampsia. Am. J. Obstet. Gynecol. 180:1146-1150.

40. Faas, M.M., and Schuiling, G.A. 2001. Pre-eclampsia and the inflammatory response. Eur. J. Obstet. Gynecol. Reprod. Biol. 95:213-217.

41. Goldman-Wohl, D., and Yagel, S. 2002. Regulation of trophoblast invasion: from normal implantation to pre-eclampsia. Mol. Cell. Endocrinol. 187:233-238.

42. von Dadelszen, P., et al. 2002. Activated protein $\mathrm{C}$ in normal human pregnancy and pregnancies complicated by severe preeclampsia: a therapeutic opportunity? Crit. Care Med. 30:1883-1892.

43. Dhainaut, J.F., et al. 2003. Drotrecogin alfa (activated) (recombinant human activated protein $\mathrm{C}$ ) reduces host coagulopathy response in patients with severe sepsis. Thromb. Haemost. 90:642-653. 44. Ogasawara, M., Sasa, H., Kajiura, S., Aoki, K., and Yagami, Y. 1995. Successful management of congenital protein $\mathrm{C}$ deficiency with recurrent pregnancy loss. Int. J. Gynaecol. Obstet. 50:185-187.

45. Richards, E.M., Makris, M., and Preston, F.E. 1997. The successful use of protein $\mathrm{C}$ concentrate during pregnancy in a patient with type 1 protein $C$ deficiency, previous thrombosis and recurrent fetal loss. Br. J. Haematol. 98:660-661.

46. Idusogie, E., Rosen, E.D., Carmeliet, P., Collen, D., and Castellino, F.J. 1996. Nucleotide structure and characterization of the murine blood coagulation factor VII gene. Thromb. Haemost. 76:957-964.

47. Stauffer, D.R., Chukwumezie, B.N., Wilberding, J.A., Rosen, E.D., and Castellino, F.J. 1998. Characterization of transcriptional regulatory elements in the promoter region of the murine blood coagulation factor VII gene. J. Biol. Chem. 273:2277-2287. 